\title{
Hand Hygiene: Adherence Influenced by Knowledge and Subjective Norms
}

\author{
C. Ruef
}

The relatively low rate of adherence to the indications for hand hygiene, despite various efforts in hospitals, is puzzling. Lack of time is frequently cited as a reason not to perform hand hygiene. Another reason is the unavailability of hand disinfectant solution at the bedside of the patient. These issues have been addressed by promoting the use of alcoholic hand rub, which requires less time to apply than soap and water and can be provided at the bedside. Nevertheless, adherence rates are frequently reported to be less than $50 \%$, especially among physicians. For several years now, the World Health Organization (WHO) has been promoting hand hygiene through its First Global Patient Safety Challenge of "Clean Care is Safer Care" [1].

In this issue of Infection, Tai et al. [2] report the results of a multi-center exploratory study in Hong Kong, which investigated the perceptions of nurses and physicians on the topic of healthcare-associated infections and hand hygiene. The study was conducted in four acute care hospitals and the results are based on a total of 1,022 questionnaires. The overall response rate was $59.3 \%$. While knowledge about the importance of healthcareassociated infections and their impact is widespread, the known differences among nurses and physicians in hand hygiene adherence is also reflected in their answers to the questions on the importance of healthcare-associated infections and also on their assessment of the time needed to disinfect hands. Interestingly, nurses and physicians reported a low rate of hand hygiene before direct patient contact. This finding suggests that hand hygiene is more likely to be performed when self-protection is the goal.
Variables that influence the attitude towards hand hygiene are the department in which the respondents work, their attitudes, their perceived behavioral control, and also subjective norms. Several other studies have also found that subjective norms are the most important cognitive factor with an influence on hand hygiene behavior. However, as other factors such as department assignment, attitudes, and perceived behavioral control are also important, a multi-module and multi-facet approach will be needed in order to be successful in improving the compliance of healthcare workers with hand hygiene.

The study by Tai et al. provides useful and important information to better understand the issue. The best strategy to make a big leap forward on this issue still remains to be found.

\section{References}

1. Pittet D, Donaldson L: Clean care is safer care: the first global challenge of the WHO World Alliance for Patient Safety. Am J Infect Control 2005; 33: 476-479.

2. Tai JWM, Mok ESB, Ching PTY, Seto WH, Pittet D: Nurses and physicians' perceptions of the importance and impact of healthcare-associated infections and hand hygiene: a multicenter exploratory study in Hong Kong. Infection 2009; 37: 320-333. 